\title{
ESTUDO BIBLIOGRÁFICO DE PUBLICAÇÕES SOBRE A ATIVIDADE ADMINISTRATIVA DA ENFERMAGEM EM SAÚDE MENTAL
}

Neide Marina Feijó Bertoncello ${ }^{1}$

Flávia Cristina Pertinhes Franco ${ }^{2}$

Bertoncello NMF, Franco FCP. Estudo bibliográfico de publicações sobre a atividade administrativa da enfermagem em saúde mental. Rev Latino-am Enfermagem 2001 setembro-outubro; 9(5):83-90.

Objetivando estudar a atividade administrativa do enfermeiro em saúde mental enquanto um instrumento do processo de trabalho, realizamos um estudo bibliográfico de publicações de enfermagem sobre esta temática no período de 1988 a 1997. Através da leitura e análise crítica de 8 artigos e 19 dissertações e teses selecionadas, identificamos as principais características dessa prática, quais sejam: os enfermeiros são os responsáveis pela equipe e assistência de enfermagem, obedecendo à lógica determinada pela instituição; suas ações não são planejadas, coordenadas e avaliadas; as atividades administrativas utilizam a maior parte de seu tempo de trabalho e o cuidado direto de enfermagem é realizado pela equipe auxiliar de enfermagem, sendo que nos serviços extra-hospitalares os atendimentos diretos e grupais são mais freqüentes.

PALAVRAS CHAVE: enfermagem psiquiátrica, saúde mental, administração

\section{BIBLIOGRAPHIC STUDY ON PUBLICATIONS CONCERNING NURSING MANAGEMENT ACTIVITIES IN MENTAL HEALTH SERVICES}

Aiming at studying the mental health nurse's management activity as an instrument in the work process, a bibliographic study on nursing publications from 1988 to 1997 which concerned that topic was carried out. By reading and critically analyzing 8 articles and 19 selected theses and dissertations, the major characteristics of such practice were identified, namely: mental health nurses are responsible for the nursing team and care according to the logic determined by the institution; their actions are not planned, coordinated or evaluated; management activities take most of their time and direct nursing care is given by the auxiliary nursing team whilst in extra-hospital services, direct and group care are more frequent.

KEY WORDS: psychiatric nursing, mental health, management

\section{ESTUDIO BIBLIOGRÁFICO DE PUBLICACIONES SOBRE LA ACTIVIDAD ADMINISTRATIVA DE ENFERMERIA EN SALUD MENTAL}

Buscando estudiar la actividad administrativa del enfermero en salud mental como un instrumento del proceso de trabajo, realizamos un estudio bibliográfico de las publicaciones de enfermería sobre ésta temática en la fecha de 1988 a 1997. A través de la lectura y el análisis crítico de 8 artículos y 19 disertaciones y tesis seleccionadas, identificamos las principales características de esa práctica, son estas: los enfermeros son los responsables por el equipo y asistencia de enfermería, obedeciendo a la lógica determinada por la institución; sus acciones no son planeadas, coordinadas y evaluadas; las actividades administrativas utilizan la mayor parte de su tiempo de trabajo y el cuidado directo de enfermería es realizado por el equipo auxiliar de enfermería. En los servicios extra-hospitalarios la atención directa y grupal es más frecuente.

PALABRAS CLAVES: enfermería psiquiátrica, salud mental, administración

\footnotetext{
${ }^{1}$ Professor Doutor, e-mail: nfeijo@fmb.unesp.br; ${ }^{2}$ Aluna do quarto ano, bolsista PIBIC/CNPq. Curso de Graduação em Enfermagem da Faculdade de Medicina de Botucatu - UNESP
} 


\section{INTRODUÇÃO}

A função administrativa do enfermeiro está prevista, com ênfase, na Lei n ${ }^{\circ} 7498$, de 25 de junho de 1986, que regulamenta o seu exercício profissional. Em seu Art. 11, define o que cabe privativamente ao enfermeiro e com relação à função de gerenciamento podemos citar, por exemplo: "planejamento, organização, coordenação, execução e avaliação dos serviços de assistência de Enfermagem" ${ }^{\text {"(1). }}$.

A função de gerência pode dar ao enfermeiro uma certa ilusão de autonomia profissional por uma relativa autoridade decisória mas, na verdade, suas ações estão submetidas ao administrador das instituições de saúde e visam, com muita freqüência, o controle de pessoal, a ordem, o cumprimento das normas já estabelecidas, 0 menor custo, etc., ficando em segundo plano a finalidade de administrar para assistir melhor ao cliente.

Essas questões não são carregadas de sentido negativo, elas são características de uma profissão que, ao longo de sua história, foi sendo condicionada dessa forma. 0 importante é não omitir essa discussão, e sim aprofundá-la, para poder ser cada vez mais sujeito na história da profissão.

Com isso, estudaremos o significado da atividade administrativa do enfermeiro, como esta é apreendida, enquanto um instrumento do processo de trabalho em saúde mental e a que finalidade responde na organização tecnológica do trabalho, tendo como objetivo analisar criticamente a produção científica sobre a administração* de enfermagem em serviços de saúde mental, através de revisão bibliográfica ${ }^{(2)}$.

\section{FUNDAMENTAÇÃO TEÓRICA E METODOLOGIA}

A Enfermagem é entendida como um trabalho, isto é, uma atividade humana que possibilita a reprodução da existência e a satisfação de necessidades, materiais e não-materiais. Como toda atividade humana pressupõe determinações históricas e sociais ${ }^{(3)}$.

Neste estudo, utilizamos o conceito de Processo de Trabalho ${ }^{(4)}$ para facilitar a compreensão da função administrativa no processo de trabalho do Enfermeiro, buscando entender sua concepção, sua finalidade e seus produtos ou resultados.

Para estudar o significado da atividade administrativa do enfermeiro em saúde mental, como esta é apreendida enquanto um instrumento do processo de trabalho em saúde, e a que finalidade responde na organização tecnológica do trabalho, realizamos uma análise dos artigos sobre essa temática, publicados nos principais periódicos de Enfermagem brasileiros, das dissertações de mestrado e teses de doutorado, no período de 10 anos, entre 1988 a 1997.

A técnica principal da pesquisa foi o estudo bibliográfico da produção científica da Enfermagem, conforme a seguinte definição: "a produção científica de uma categoria profissional revela a ideologia da mesma, o seu direcionamento técnico, científico e político, as preocupações centrais e subjacentes da profissão e ainda revela 0 que está se passando na realidade prática"(5).

Como técnica, a pesquisa bibliográfica compreende a leitura, seleção, fichamento e arquivo dos tópicos de interesse para a pesquisa em pauta, com vistas a conhecer as contribuições científicas que se efetuaram sobre determinado assunto ${ }^{(6)}$.

Selecionamos 08 artigos (Anexo 1) específicos sobre Enfermagem Psiquiátrica ou de Saúde Mental, aqueles que abordavam a questão administrativa em enfermagem, sendo que na maioria das vezes de forma indireta. Com relação às dissertações e teses, buscamos a biblioteca da ABEn - Nacional, que nos forneceu as referências bibliográficas e selecionamos 19 (Anexo 2), após conhecimento dos temas tratados e resumos.

\section{DISCUSSÃO}

$\mathrm{Na}$ leitura e análise das publicações buscamos as convergências e contradições, sendo que ao organizarmos os dados destacaram-se dois tópicos principais - a administração como instrumento de trabalho e o enfermeiro, a equipe de trabalho e a instituição - os quais serão apresentados a seguir.

\section{A administração como instrumento de trabalho}

Retratando o início da enfermagem psiquiátrica no Brasil, escreve que desde os primórdios da organização das instituições e da assistência psiquiátrica, a enfermagem realizou cuidados diretos aos doentes mentais, aplicando procedimentos disciplinares que possibilitavam sujeitá-los, objetivando a manutenção da ordem dentro do espaço asilar. O modelo organizacional inicial foi centrado no saber médico que detinha o poder administrativo, com rígido controle sobre a força de trabalho em enfermagem ${ }^{(7)}$.

Cerca de um século se passou e, obviamente, a prática do enfermeiro psiquiátrico se transformou, acompanhando as mudanças

\footnotetext{
* Será generalizado o uso dos termos administração e gerenciamento, com uma aproximação à definição: "a arte de pensar, de decidir e de agir; é a arte de fazer acontecer, de obter resultados. Resultados que podem ser definidos, previstos, analisados e avaliados, mas que tem de ser alcançados através das pessoas e numa interação humana constante."(2)
} 
do setor saúde e da sociedade. Contudo, um estudo sobre o papel do enfermeiro em unidades de internação psiquiátrica, conclui que a relação deste profissional com a equipe de enfermagem e com os pacientes ainda é autoritária, reproduzindo 0 autoritarismo das instituições. Segundo a autora, cabe ao enfermeiro, nestas instituições, coordenar o cuidado de enfermagem, desenvolvendo um cuidado indireto, sendo responsável por todas as atividades da equipe de enfermagem. Informa que as principais ações do enfermeiro são: orientação em serviço, avaliação do trabalho da equipe de enfermagem, controle de faltas e escalas de plantão( ${ }^{(8)}$.

Em países mais desenvolvidos o papel do enfermeiro psiquiátrico tem se modificado nos últimos anos. Antes desempenhava apenas atividades de caráter gerencial, passando a assumir mais atividades com finalidades terapêuticas por intermédio do relacionamento terapêutico e programas de educação a pacientes e familiares, sendo que em nosso meio, esta mudança está se processando de modo lento e gradativo ${ }^{(9)}$.

Uma pesquisadora afirma que as funções realizadas por enfermeiros em ambulatório de saúde mental compreendem a coordenação do pessoal de enfermagem, treinamento e supervisão deste pessoal, atendimento individual e de emergência, atendimento grupal, desenvolvimento do relacionamento terapêutico e visita domiciliária. As atividades do enfermeiro neste trabalho foram classificadas como: administrativas, ações grupais e individuais. Entre as administrativas foram relacionadas as seguintes atividades: responsável pela manutenção de material; supervisão do pessoal de apoio técnico (recepção); pedido, encaminhamento e resultado de exames de laboratório; solicitação de ambulância; orientação e supervisão, treinamento e reciclagem da equipe de enfermagem $e$ participação em reuniões administrativas da equipe de saúde. Algumas atividades, do âmbito administrativo, foram citadas como desvio de função, quais sejam: controle de farmácia, solicitação de ambulância, pedidos e encaminhamentos de exames de laboratório e orientação e supervisão do pessoal da limpeza ${ }^{(10)}$.

As atividades burocrático - administrativas e as condições concretas de trabalho afastam os enfermeiros da relação com 0 paciente, uma vez que a organização e eficiência tornam-se mais importantes do que 0 cuidado. A autora, ainda, considera que 0 enfermeiro realiza uma multiplicidade de ações que envolve a participação na equipe, a supervisão de enfermagem, a integração nas atividades da instituição e não the resta tempo livre para atuar com os pacientes, despendendo tempo e energia na heterogeneidade do cotidiano de um fazer referido à resolução de "pequenos problemas" $^{\prime(11)}$.

Outras autoras descrevem essas ações burocrático administrativas como: pedido e controle de medicação, de roupas, lavanderia, controle de funcionários e das rotinas ${ }^{(12-13)}$.
Outro estudo define essas atividades como de secretaria e economato, e também concorda que essas ações são realizadas em detrimento daquelas de desenvolvimento pessoal e de assistência direta ao paciente ${ }^{(14)}$

A grande conseqüência identificada por ocupar o maior tempo do trabalho com atividades de cunho administrativo é o distanciamento do paciente, sendo que a assistência direta é quase exclusivamente executada pelo pessoal auxiliar, fato que leva a uma falta de reconhecimento do enfermeiro por parte da clientela e de outros profissionais ${ }^{(12,15)}$

Em um estudo encontra-se que as ações de cunho administrativo são necessárias para a prestação da assistência ao paciente. Porém, afirma que, da maneira como são desenvolvidas, estão visando o cumprimento de exigências de uma administração superior $^{(16)}$

Uma autora, em seu estudo, mostra que as ações que os enfermeiros descrevem como sendo suas, recaem na função administrativa, em primeiro lugar, e técnica logo a seguir. A função terapêutica foi considerada em terceiro lugar com uma porcentagem muito inferior à das ações que foram consideradas como administrativas. Também foi baixa a porcentagem encontrada nas funções de educadores e de agente socializador ${ }^{(17)}$.

As autoras anteriormente citadas, apontam com bastante clareza que os Enfermeiros desenvolvem, em suas práticas, quer intra ou extra-hospitalar, funções administrativas, porém não descrevem se essas ações estão sendo realizadas de forma efetivamente planejada, sugerindo que não estão realmente voltadas para a melhoria da assistência de enfermagem e da saúde mental, e sim para o controle e manutenção da ordem nos serviços.

Uma pesquisadora corrobora com essa idéia, ao dizer que o papel do enfermeiro é o cuidado indireto, pois o cuidado direto (higienização, alimentação, administração de medicamentos, etc) é executado pelos outros integrantes da equipe de enfermagem, os quais permanecem o maior tempo junto aos pacientes. Além disso, refere que esse cuidado indireto é realizado de forma autoritária, reproduzindo o autoritarismo das instituições, sendo que "... tal divisão não dá primazia ao técnico, mas ao social, tendo em vista que não considera o nivel de complexidade das tarefas, mas a racionalização dos custos, base em que assenta o acúmulo de capital”(8).

Ainda no mesmo trabalho encontramos que os enfermeiros das instituições psiquiátricas estudadas desenvolvem esporadicamente as ações de cuidado direto, como estimulação à alimentação e acompanhamento individual, sendo que essa última não é desejada pela instituição e por vezes proibida ${ }^{(8)}$.

Um estudo sobre a percepção que o doente mental tem a respeito da assistência desenvolvida pelo enfermeiro, traz conclusões parecidas, isto é, que seu trabalho no hospital estudado "restringe- 
se mais às funções administrativas, ficando os pacientes aos cuidados de atendentes e auxiliares de enfermagem", sendo que não há identificação clara do enfermeiro por parte dos pacientes, porque não há aproximação entre eles ${ }^{(18)}$.

Vários outros autores identificam a administração como uma das funções principais do enfermeiro, citando especialmente a responsabilidade pela assistência e a supervisão do pessoal auxiliar.

Assim, defendem que esse é um papel importante do enfermeiro, do qual ele não deve abrir mão, sendo que o consideram importante tanto na supervisão do pessoal auxiliar como na assistência de enfermagem prestada ao doente mental ${ }^{(19)}$.

Ainda, dizem que cabe aos enfermeiros viabilizar a melhoria da assistência, citam como estratégias algumas funções administrativas, entre elas a supervisão das ações desempenhadas pelos funcionários da enfermagem ${ }^{(13)}$.

Reforçando a mesma idéia afirmam que nas instituições hospitalares as ações de enfermagem ficam concentradas na área administrativa, enquanto que na rede extra-hospitalar há uma expansão dessas ações, estando elas entre as funções de assistência, administração e educação ${ }^{(20)}$.

Embora a maior parte dos trabalhos aponte para o fato de que o enfermeiro esteja desempenhando, na maior parte do tempo, atividades administrativas nas instituições psiquiátricas em que atuam, alguns autores fazem uma espécie de chamamento, para que essa função esteja voltada para o planejamento e organização da assistência.

Por exemplo, afirmando que o enfermeiro pode realizar ações terapêuticas, além de exercer seu papel de coordenador, especialmente porque permanece grande parte do dia na instituição, com maior oportunidade de contato com os pacientes ${ }^{(16)}$.

Ainda tentando justificar as ações administrativas como aquelas que podem melhorar a assistência prestada, esperam que 0 enfermeiro, além de desempenhar funções terapêuticas, seja agente de mudanças, interferindo no ambiente hospitalar, tornando-o terapêutico e conclui que a atividade predominante do enfermeiro psiquiátrico é o de organizar o serviço de enfermagem, pelo qual é responsável ${ }^{(21)}$.

Autores reforçam a importância da função administrativa do enfermeiro ser realizada de forma planejada, organizada, sistematizada, possibilitando o exercício do seu papel de orientador e supervisor na busca pela melhoria da assistência prestada ${ }^{(9,22-23)}$.

Esse ideal para o enfermeiro é contraposto pela organização do trabalho, a qual define o papel que cada membro vai desempenhar na equipe multiprofissional, e esse "jogo" de relações acaba por instituir ao enfermeiro um trabalho de "apaga fogo", "tapa buraco", na corrida por cobrir as alas das instituições ${ }^{(11)}$.

Em suas afirmações a mesma autora traz, implicitamente, uma das dificuldades para o desempenho da função do enfermeiro, seja ela assistencial ou administrativa, isto é, afirma que o enfermeiro tem que cobrir diversas alas, de acordo com a lógica das instituições que, em geral, contratam poucos enfermeiros, que ficam responsáveis por inúmeros setores, sem ter condições de desenvolver um trabalho desejável( ${ }^{(11)}$.

A prática administrativa evidenciada nos trabalhos estudados não é apresentada como sendo realizada de forma planejada, organizada e voltada para um fim claramente definido. Não foi observada nenhuma referência sobre a avaliação da assistência prestada, como parte da função administrativa desse profissional.

Uma possibilidade de se realizar a avaliação, seria através das anotações de enfermagem, porém, essas estão sendo realizadas, em sua maioria, por pessoal de enfermagem com menor qualificação, de maneira telegráfica, pouco clara e subjetiva ${ }^{(24)}$. Com isso, a avaliação, como parte do processo gerencial, que consideramos necessária, não poderia ser realizada através das anotações de enfermagem.

A função administrativa que o enfermeiro exerce poderia e deveria estar voltada para a melhoria da assistência ao cliente. Contudo o que se identifica nas leituras realizadas, é que, geralmente, essa função serve para a transmissão de "ordens e regulamentos emanados pelo corpo clínico e pela administração, ficando, portando a ênfase de seu trabalho voltada para a determinação de tarefas a serem cumpridas..."(21). Semelhante conclusão é a de que a "enfermeira atua apenas como um instrumento de reprodução da ideologia da instituição"(8).

É interessante transcrever algumas expressões que foram apresentadas pelas enfermeiras entrevistadas em uma das publicações analisadas, para denominar a função que exerciam na instituição onde atuavam: "um papel burocrático", "um papel de cumprir ordens", "de botar ordem no galinheiro", "governanta", "manutenção da ordem total", "administrativo" e de "submisso e autoritário"(8)

Ao administrar cumprindo as exigências da administração superior dos serviços de saúde mental, o enfermeiro tem sua função desviada, gerenciando os problemas acarretados pelas deficiências de infra-estrutura. Algumas conseqüências dessa prática tem sido 0 afastamento do enfermeiro das ações de cuidado direto ao cliente e a falta de reconhecimento de seu trabalho por parte da clientela e equipe de trabalho.

\section{O Enfermeiro, a equipe de trabalho e a instituição}

O trabalho em saúde e portanto, o trabalho do enfermeiro, é coletivo: ele se relaciona, interfere e recebe interferência do trabalho 
das demais profissionais da saúde. Na saúde mental, o trabalho em equipe multiprofissional é um ponto forte das orientações para a área. O enfermeiro, além de compor essa equipe, também tem relações estreitas com outros trabalhadores da enfermagem.

Nas referências estudadas encontramos a afirmação de que 0 trabalho em equipe não é enfatizado nem na formação do enfermeiro, sendo que "o aluno desenvolve atividades isoladas; as vezes faz contato com algum profissional, apenas para obter informações complementares. São poucas as iniciativas de desenvolvimento de trabalho conjunto"(25).

A questão do trabalho em equipe em ambulatórios de saúde mental é vista como uma contradição, sendo que algumas enfermeiras entrevistadas em uma pesquisa, apontam esse relacionamento como uma facilidade e outras como dificuldade. As últimas referem que há "falta de visão dos membros da equipe sobre o papel da enfermeira; dificuldade de entrosamento com os médicos, devido a carga horária destes ser reduzida; falta de entrosamento entre os membros da equipe multiprofissional, bem como dificuldade de relacionamento da enfermeira com 'membros problemáticos' da equipe de enfermagem"(10).

O estudo acima referido apresenta outras dificuldades relativas ao relacionamento do enfermeiro com sua equipe de trabalho, que atrapalham o desempenho de seu papel administrativo, quais sejam: abuso de autoridade por parte da pessoa responsável pelo ambulatório, não aceitação do enfermeiro como chefe do serviço, rotatividade do pessoal, entre outras.

A maioria dos estudos que abordou a questão da prática do enfermeiro e sua participação junto à equipe multiprofissional e de enfermagem, aponta para uma situação conflituosa desse trabalho.

Autoras referem que há conflitos entre todas as categorias profissionais, referindo que dentro de uma estrutura tradicional, os profissionais estão imbuídos de uma concepção reducionista da doença e do doente mental. Para as autoras, além do enfermeiro possuir concepções equivalentes às dos demais profissionais, estava mal integrado na instituição hospitalar que estudaram, a qual não reconhecia o seu papel profissional e não oferecia condições para que atuasse dentro da área específica de sua competência ${ }^{(13,17)}$.

A dificuldade de posicionamento do enfermeiro na equipe multiprofissional é justificada pelo fato de que a equipe não possui um objetivo de trabalho único, sendo que cada profissional trabalha com um referencial teórico diferente, o que vem prejudicar também a visão integral do paciente, o qual é abordado de forma fragmentada ${ }^{(12)}$.

Em um dos estudos encontramos visões contraditórias de enfermeiros sobre sua inserção na equipe de trabalho, predominando, contudo, os aspectos negativos, como: interferências das chefias das instituições sobre o trabalho desenvolvido; preferência dos enfermeiros pelas atividades administrativas; excesso de reuniões; resistência dos auxiliares de enfermagem sobre suas atuações; corporativismo médico; regalias para alguns funcionários; falta de respeito e desvalorização do trabalho dos enfermeiros, entre outras questões ${ }^{(20)}$.

Por outro lado, o estudo citado acima, identificou enfermeiros que visualizaram pontos positivos no trabalho em equipe, referindo autonomia no desenvolvimento de seu trabalho, com apoio e respeito da diretoria das instituições, considerando que era possível a atuação da enfermagem em equipes multiprofissionais. Estas considerações se deram, especialmente, em instituições públicas de saúde mental ${ }^{(20)}$.

A relação de submissão do enfermeiro nas instituições de saúde mental é apontada por diversos trabalhos. Por exemplo, há destaque sobre a dificuldade de relacionamento com os médicos e a ordem institucional, impondo a submissão e o servilismo ${ }^{(20)}$.

Essa questão é histórica, sendo que ao médico da instituição sempre coube a direção do hospício e ao enfermeiro o cumprimento de suas ordens. Assim, o enfermeiro sempre ocupou posição intermediária entre o médico e o paciente, tornando-se um profissional importante à nova linha da assistência mental que se formou no capitalismo ${ }^{(26)}$.

No plano prático, vários estudos identificam conflitos e dificuldades do enfermeiro em sua inserção na equipe de saúde mental, assim como de desenvolver as funções que teoricamente Ihe são atribuídas, especialmente, o relacionamento terapêutico.

Encontramos considerações acerca da posição do enfermeiro nas instituições psiquiátricas, concordando com um posicionamento de "subprivilegiados" nas instituições, por um lado cumprindo ordens impostas e, por outro, privilegiados na equipe de enfermagem ${ }^{(16)}$.

Há conflitos no relacionamento do enfermeiro com a equipe de enfermagem, por exemplo, na questão de que os auxiliares buscam outros profissionais da equipe de saúde mental para esclarecer suas dúvidas, não considerando os enfermeiros como orientadores de sua prática ${ }^{(17)}$. Isso também foi verificado em outros estudos que identificaram que 0 auxiliar de enfermagem atua mais como auxiliar do médico, buscando facilitar o trabalho do mesmo e recorrendo a ele quando tinham alguma dúvida no trabalho ${ }^{(15,19)}$.

Alguns estudos não visualizam o enfermeiro como elo entre os profissionais, referindo a existência de uma prática solitária com sobrecarga de trabalho. Outros que observam o enfermeiro inseridos na equipe, especialmente em locais onde os enfermeiros desenvolvem o contato direto com a assistência ${ }^{(16,23)}$.

Com relação à divisão de trabalho na enfermagem, os atendentes e auxiliares de enfermagem realizam ações de higiene, alimentação, hidratação, conforto, observação, verificação de sinais vitais, controle de peso e eliminações, medicações e 
encaminhamentos para outros setores, enquanto que o enfermeiro participa no atendimento de situações que exigem maior responsabilidade e conhecimentos técnico-científicos e responde pelas atividades administrativas da clínica ${ }^{(17)}$.

Um estudo sobre como os auxiliares de enfermagem descrevem o enfermeiro, identifica uma contradição: enquanto um grupo define o enfermeiro como um profissional que apoia, auxilia, transmite segurança, outros auxiliares o descrevem como um profissional distante dos pacientes e funcionários, burocrata $\mathrm{e}$ autoritário ${ }^{(11)}$. Essas divergências estão relacionadas às atitudes dos enfermeiros e à sua proximidade ou distanciamento dos pacientes $\mathrm{e}$ funcionários $^{(17)}$.

Em tese, o discurso institucional vê o enfermeiro como técnico de referência para atendimento aos pacientes, semelhante aos demais profissionais de nível superior, entretanto, na prática concreta ele não consegue exercer esse papel de atendimento direto ao paciente, restringindo suas ações na coordenação da equipe de enfermagem, acompanhando o cotidiano da enfermaria, mas não se sentindo reconhecido pelos outros profissionais como um técnico igual a eles. Tal imagem do enfermeiro se estrutura no seu imaginário a partir da consciência de que, efetivamente, não realiza o trabalho nobre da instituição, que dá status ao profissional - "ser referência de

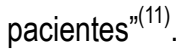

A autora da citação acima, ao descrever as atividades dos enfermeiro nos NAPS (Núcleo de Atenção Psico-Social), nos mostra uma realidade um pouco diferente das instituições hospitalares de saúde mental, afirmando que, naquelas instituições, os enfermeiros centram-se no atendimento aos pacientes, através de sua inserção nas atividades grupais e individuais e na supervisão dos auxiliares de enfermagem ${ }^{(11)}$. Conclusões semelhantes foram encontradas em um estudo sobre a prática do enfermeiro em hospitais-dia psiquiátricos ${ }^{(27)}$.

A vinculação do enfermeiro com tarefas burocráticas, além de 0 distanciar do cuidado direto ao paciente, acaba acarretando desgaste pessoal, tornando-o angustiado e insatisfeito ao desempenhar papéis de "tarefeiro", "quebra-galho" ou "bombeiro", sendo que, na realidade, ele está gerenciando crises, com o intuito de superar as deficiências de infra-estrutura. Neste sentido, sentese mais vinculado ao setor administrativo do hospital ${ }^{(13)}$.

Em algumas instituições estudadas verificou-se que não há trabalho em equipe, as relações de trabalho são hierarquizadas e o médico situa-se no ponto mais alto desta hierarquia, e o enfermeiro, sendo assalariado, vende a sua força de trabalho, numa posição de subordinação aos proprietários dos meios de produção( ${ }^{(8)}$.

Outros autores buscaram justificativas para as dificuldades do trabalho em equipe. Por exemplo: dificuldades do trabalho em equipe com a falta de bons líderes ${ }^{(22)}$ e posição ambígua do enfermeiro por seu duplo vínculo (equipe multiprofissional/ coordenação de enfermagem e demanda da enfermaria) exigido pela instituição onde está inserido ${ }^{(26)}$

Outra justificativa apresentada para essas dificuldades é a de que o enfermeiro, absorvido pela hierarquização do cotidiano, tenta encaminhar, dar um retorno às solicitações que lhes são feitas, com um comportamento de onipotência de ter que dar respostas a tudo e a todos. Mas, seu falso poder é desmistificado diante da diluição de suas ações em tarefas que não são prioritárias e, muitas vezes, são da competência de outros. Isso tudo é reforçado pela tendência e estereótipo do enfermeiro em abarcar coisas e da instituição o ver como alguém para resolver os problemas ${ }^{(11)}$.

Continuando, a autora refere que só aparentemente 0 trabalho do enfermeiro é desenvolvido em equipe de forma coletiva, cabendo a este profissional o trabalho "sujo", duro e solitário. Ela acredita que essa situação pode ser revertida quando a equipe tomar consciência dessa divisão do trabalho e propor uma produção coletiva, buscando uma reestruturação, mudando as regras do jogo, onde os enfermeiros possam assumir uma postura mais ativa, aprendendo no cotidiano outro jeito de trabalhar que "não mais a corrida para a cobertura das alas". Em outras palavras, considera que o espaço do enfermeiro não está dado, é um espaço a ser conquistado ${ }^{(11)}$.

\section{CONCLUSÕES}

Nesse tópico destacamos os pontos mais freqüentes discutidos pelos autores, os quais vão ao encontro dos pressupostos iniciais desse estudo.

Os diversos autores, em sua grande maioria, evidenciaram que o enfermeiro é o profissional da equipe de saúde mental que menos realiza atendimentos diretos à clientela, ocupando a maior parte de seu tempo com atividades de organização do trabalho das instituições onde atua. Suas atividades são, então, auxiliares e instrumento para a prática dos demais profissionais da equipe, através da supervisão da equipe de enfermagem e recepção e providências a respeito da infra-estrutura para os demais atendimentos.

Em suas ações administrativas, o enfermeiro atua como gerente intermediário entre a equipe e a administração superior das instituições de saúde mental. No entanto, exerce essa função sem reconhecimento formal da direção e equipe de saúde ${ }^{(15)}$.

Os trabalhos que tiveram as instituições extra-hospitalares como campo de estudo, mostram uma tendência de mudança na prática dos enfermeiros, especialmente, relativas à sua aproximação do cliente, desenvolvendo práticas terapêuticas e grupais, assim como um espaço mais definido e reconhecido na equipe de saúde mental.

Como instrumento de trabalho do enfermeiro, o 
gerenciamento não tem sido utilizado com todas as suas possibilidades, especialmente com a finalidade de atender às necessidades de promoção de saúde da clientela atendida nos serviços de saúde mental. A ausência de um plano de trabalho com objetivos definidos afeta a todos os membros das equipes de saúde mental que trabalham de forma fragmentada, não tendo clareza de

Anexo 1

\section{RELAÇÃO DOS ARTIGOS SELECIONADOS PARA O ESTUDO}

Barros S, Rolim MA. O ensino de enfermagem psiquiátrica e a lei do exercício profissional da enfermagem. Rev Latino-am Enfermagem 1996 janeiro;4(1):47-54.

Filizola CLA. O papel do enfermeiro psiquiatra-oprimido e opressor. Rev Esc Enfermagem da USP 1997 agosto;.31(2):173-90.

Galera SAF, Capelari RT, Barros S. Estudo das anotações de enfermagem em uma emergência psiquiátrica. Rev Paul Enfermagem 1991 janeiro/abril; 10(1):3-12

\section{Anexo 2}

\section{RELAÇÃO DAS DISSERTAÇÕES DE MESTRADO E TESES DE DOUTORADO SELECIONADAS PARA O ESTUDO}

Aguiar MGG. A reinvenção do ser enfermeira no cotidiano da Casa de Saúde Anchieta e núcleos de atenção psicossocial. [dissertação]. São Paulo (SP): Escola de Enfermagem/USP; 1995.

Alencastre MB. Como o pessoal de enfermagem psiquiátrica vê o profissional enfermeiro - uma abordagem compreensiva. [tese]. Ribeirão Preto (SP): Escola de Enfermagem de Ribeirão Preto/USP; 1990.

Bertoncello NMF. O processo de trabalho em ambulatório de saúde mental: a prática da enfermeira. [tese]. Ribeirão Preto (SP): Escola de Enfermagem de Ribeirão Preto/USP; 1997.

Bressan VR. O cuidado ao doente mental crônico na perspectiva do enfermeiro: uma abordagem fenomenológica. [dissertação]. Ribeirão Preto (SP): Escola de Enfermagem de Ribeirão Preto/USP; 1998.

Campos CJG. $\mathrm{O}$ atendimento do doente mental em pronto-socorro geral: sentimentos e ações dos membros da equipe de enfermagem. [dissertação]. São Paulo (SP): Escola de Enfermagem/USP; 1996.

Chama RC. Ensino teórico prático de enfermagem psiquiátrica e saúde mental nos cursos de graduação em enfermagem da grande São Paulo. [dissertação]. São Paulo (SP): Escola de Enfermagem/USP; 1997.

Colvero LA. O significado do "ser enfermeiro" em ambulatório de saúde mental. [dissertação]. São Paulo (SP): Escola de Enfermagem/USP; 1994. Fraga MNO. A prática de enfermagem psiquiátrica: subordinação e resistência. [tese]. Ribeirão Preto (SP): Escola de Enfermagem de Ribeirão Preto/USP; 1993

Marcolan JF. Opinião dos enfermeiros que atuam em enfermagem psiquiátrica e em saúde mental no município de São Paulo sobre suas ações. [dissertação]. São Paulo (SP): Escola de Enfermagem/USP; 1996.

\section{REFERÊNCIAS BIBLIOGRÁFICAS}

\section{COREn (SP). Lei n. 7498, de 25 de junho de 1986. Dispõe sobre a} regulamentação do exercício da enfermagem e dá outras providências. In: COREn (SP). Documentos básicos de enfermagem: enfermeiros, técnicos, auxiliares. São Paulo; 1997.

2. Motta PR. Gestão contemporânea: a ciência e a arte de ser dirigente. $7^{\text {a }}$ ed. Rio de Janeiro (RJ): Record; 1996. onde querem chegar e nem dos resultados de seus trabalhos.

As considerações aqui apresentadas indicam a importância da temática na análise da prática dos enfermeiros e a necessidade de reflexão e busca contínua e coletiva para a superação de suas contradições e conflitos, assim como para a utilização consciente e adequada desse instrumento de trabalho: a administração.

Kirschbaun DIR. A análise histórica das práticas de enfermagem no campo da assistência psiquiátrica no Brasil, no período compreendido entre as décadas de 20 e 50. Rev Latino-am Enfermagem 1997 maio; 5:19-30.

Pagotto MC, Luis MV. A percepção do doente mental a respeito do enfermeiro e da assistência recebida. Rev Paul Enfermagem 1988 abril/maio/junho; 8(2):17-22.

Pontes PAR, Fraga MNO. Reforma psiquiátrica no Ceará: descrição de um caso. Rev Latino-am Enfermagem 1997 maio; 5:45-50.

Rocha M. Enfermagem psiquiátrica: que papel é este? Rev Enfermagem UERJ 1993 novembro; 1(2):9-23

Rolim MA, Barros S, Stfanelli MC, Texeira MB. O enfermeiro em ambulatório de saúde mental. Rev Esc Enfermagem USP 1192 dezembro; 26(3):289302.

Mello IM. Proposta de orientação para sistematização de assistência de enfermagem psiquiátrica. [dissertação]. São Paulo (SP): Escola de enfermagem/USP;1998.

Ogata MN. Contribuição à história da enfermagem psiquiátrica brasileira. [dissertação]. Ribeirão Preto (SP): Escola de Enfermagem de Ribeirão Preto/ USP;1992

Pedrão LJ. Certezas e dúvidas do enfermeiro de unidade de psiquiatria de Hospital Geral. [dissertação]. Ribeirão Preto (SP): Escola de Enfermagem de Ribeirão Preto/USP; 1990

Pedrão LJ. Avaliação da escala de observação intensiva para pacientes psiquiátricos internados aplicada rotineiramente em uma unidade de psiquiatria de Hospital Geral. [tese]. Ribeirão Preto (SP): Faculdade de Medicina de Ribeirão Preto/USP;1997.

Pitiá ACA. O enfermeiro e seu cotidiano - cenas de um manicômio. [dissertação]. Ribeirão Preto (SP): Escola de Enfermagem de Ribeirão Preto/ USP;1997.

Rolim MA. As apresentações sociais acerca do doente mental atendido em emergência psiquiátricas. [tese]. São Paulo (SP):Escola de Enfermagem/ USP; 1993

Rossini MGC. Estudo da prática do enfermeiro em hospitais - dia psiquiátricos. [dissertação]. Ribeirão Preto (SP): Escola de Enfermagem de Ribeirão Preto/ USP;1998

Saeki T. Análise da prática do enfermeiro em um hospital psiquiátrico. [tese] Ribeirão Preto (SP): Escola de Enfermagem de Ribeirão Preto/USP; 1994. Silva EM. Supervisão em enfermagem: análise crítica das publicações no Brasil dos anos 30 à década de 80. Ribeirão Preto. [dissertação]. Ribeirão Preto (SP): Escola de Enfermagem de Ribeirão Preto/USP; 1991.

Souza MCBM. Estudo bibliográfico da produção da enfermagem psiquiátrica no Brasil, no período de 1932 a 1993. [dissertação]. Ribeirão Preto (SP): Escola de Enfermagem de Ribeirão Preto/USP; 1995.

3. Almeida MCP. O saber de enfermagem e sua dimensão prática. São Paulo (SP): Cortez; 1986

4. Marx K. O capital: crítica da economia política. São Paulo (SP): Nova Cultura; 1985.

5. Carrasco MAP, Influência das Escolas de Administração Clássica e Científica na produção científica da enfermagem brasileira. [dissertação]. Ribeirão Preto (SP): Escola de Enfermagem de Ribeirão Preto/USP; 1987. 
6. Ferrari AT. Metodologia da pesquisa científica. São Paulo (SP):

McGraw-Hill do Brasil; 1982.

7. Kirschbaun DIR. A análise histórica das práticas de enfermagem no campo da assistência psiquiátrica no Brasil, no período compreendido entre as décadas de 20 e 50. Rev Latino-am Enfermagem 1997 maio;5:19-30.

8. Filizola CLA. O papel do enfermeiro psiquiatra-oprimido e opressor. Rev Esc Enfermagem da USP 1997 agosto;:31(2):173-90.

9. Mello IM. Proposta de orientação para sistematização de assistência de enfermagem psiquiátrica. [dissertação]. São Paulo (SP): Escola de enfermagem/USP;1998.

10. Rolim MA, Barros S, Stefanelli MC, Texeira MB. O enfermeiro em ambulatório de saúde mental. Rev Esc Enfermagem USP 1992 novembro; 26(3):289-302.

11. Aguiar MGG. A reinvenção do ser enfermeira no cotidiano da Casa de Saúde Anchieta e núcleos de atenção psicossocial. [dissertação]. São Paulo (SP): Escola de Enfermagem/USP; 1995.

12. Bressan VR. $O$ cuidado ao doente mental crônico na perspectiva do enfermeiro: uma abordagem fenomenológica. [dissertação]. Ribeirão Preto (SP): Escola de Enfermagem de Ribeirão Preto/USP; 1998.

13. Saeki T. Análise da prática do enfermeiro em um hospital psiquiátrico. [tese]. Ribeirão Preto (SP): Escola de Enfermagem de Ribeirão Preto/USP; 1994.

14. Silva EM. Supervisão em enfermagem: análise crítica das publicações no Brasil dos anos 30 à década de 80 . Ribeirão Preto. [dissertação]. Ribeirão Preto (SP): Escola de Enfermagem de Ribeirão Preto/USP; 1991.

15. Bertoncello NMF. O processo de trabalho em ambulatório de saúde mental: a prática da enfermeira. [tese]. Ribeirão Preto (SP): Escola de Enfermagem de Ribeirão Preto/USP; 1997.

16. Pitiá ACA. O enfermeiro e seu cotidiano - cenas de um manicômio. [dissertação]. Ribeirão Preto (SP): Escola de Enfermagem de Ribeirão Preto/USP;1997.
17. Alencastre MB. Como o pessoal de enfermagem psiquiátrica vê o profissional enfermeiro - uma abordagem compreensiva. [tese]. Ribeirão Preto (SP): Escola de Enfermagem de Ribeirão Preto/USP; 1990.

18. Pagotto MC, Luis MV. A percepção do doente mental a respeito do enfermeiro e da assistência recebida. Rev Paul Enfermagem 1988 abril/maio/junho; 8(2):17-22.

19. Rolim MA. As apresentações sociais acerca do doente mental atendido em emergência psiquiátricas. [tese]. São Paulo (SP):Escola de Enfermagem/USP; 1993.

20. Marcolan JF. Opinião dos enfermeiros que atuam em enfermagem psiquiátrica e em saúde mental no município de São Paulo sobre suas ações. [dissertação]. São Paulo (SP): Escola de Enfermagem/ USP; 1996.

21. Saeki T. Caracterização das atividades do enfermeiro na assistência ao doente mental internados nos hospitais psiquiátricos do estado de São Paulo. [dissertação]. Ribeirão Preto (SP): Escola de Enfermagem de Ribeirão Preto/USP; 1981.

22. Pedrão LJ. Certezas e dúvidas do enfermeiro de unidade de psiquiatria de Hospital Geral. [dissertação]. Ribeirão Preto (SP): Escola de Enfermagem de Ribeirão Preto/USP; 1990.

23 Souza MCBM. Estudo bibliográfico da produção da enfermagem psiquiátrica no Brasil, no período de 1932 a 1993. [dissertação]. Ribeirão Preto (SP): Escola de Enfermagem de Ribeirão Preto/USP; 1995.

24. Galera SAF, Capelari RT, Barros S. Estudo das anotações de enfermagem em uma emergência psiquiátrica. Rev Paul Enfermagem 1991 janeiro/abril; 10(1):3-12.

25. Barros S, Rolim MA. O ensino de enfermagem psiquiátrica e a lei do exercício profissional da enfermagem. Rev Latino-am Enfermagem 1996 janeiro;4(1):47-54

26. Ogata MN. Contribuição à história da enfermagem psiquiátrica brasileira. [dissertação]. Ribeirão Preto (SP): Escola de Enfermagem de Ribeirão Preto/USP;1992

27. Rossini MGC. Estudo da prática do enfermeiro em hospitais-dia psiquiátricos. [dissertação]. Ribeirão Preto (SP): Escola de Enfermagem de Ribeirão Preto/USP;1998. 